\title{
Communicative skills of children with autistic spectrum disorder: clinical and family perception
}

\author{
Fernanda Aparecida Ferreira de Freitas ${ }^{1}$ \\ https://orcid.org/0000-0002-2436-6424 \\ Ana Cristina de Albuquerque Montenegro 2 \\ https://orcid.org/0000-0001-5791-0900 \\ Fernanda Dreux Miranda Fernandes ${ }^{3}$ \\ https://orcid.org/0000-0002-3382-9427 \\ Isabelle Cahino Delgado ${ }^{4}$ \\ https://orcid.org/0000-0002-0800-559X \\ Larissa Nadjara Alves Almeida ${ }^{4}$ \\ https://orcid.org/0000-0002-6818-3398 \\ Giorvan Ânderson dos Santos Alves ${ }^{4}$ \\ https://orcid.org/0000-0003-1619-0139
}

Universidade Federal da Paraíba - UFPB, Programa de Pós-Graduação em Linguística, João Pessoa, Paraiba, Brasil. Universidade Federal de PernambucoUFPE, Departamento de Fonoaudiologia, Recife, Pernambuco, Brasil.

${ }^{3}$ Universidade de São Paulo, Faculdade de Medicina - FMUSP, Departamento de Fonoaudiologia, São Paulo, São Paulo, Brasil.

Universidade Federal da Paraíba - UFPB, Departamento de Fonoaudiologia, João Pessoa, Paraiba, Brasil.

Study developed in the Postgraduate Program in Linguistics at the Federal University of Paraíba - UFPB, João Pessoa, Paraiba, Brazil.

Conflict of interests: Nonexistent

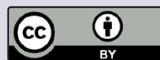

Received on: March 2,2021

Accepted on: July 21, 2021

\section{Mailing address:}

Fernanda Aparecida Ferreira de Freitas Cidade Universitária, Campus I -

Castelo Branco

CEP: 58050-085 - João Pessoa, Paraiba, Brasil

E-mail: fernandaaparecida@hotmail.com

\section{ABSTRACT}

Objective: to describe the communication skills of children with autistic spectrum disorder (ASD), considering the clinical and family perspective.

Methods: from the point of view of parents and therapists, the language of ten children with ASD was analyzed. All children underwent speech therapy at the outpatient clinic of a Speech Therapy School. Two protocols were used for data collection. Autism Treatment Evaluation Checklist (ATEC), which was applied to the children's parents, and Protocol for Assessment of Pragmatic Skills of Children with Autism Spectrum Disorders - called Pragmatic Protocol (PP), which was answered by therapists. The data were examined through a descriptive statistical analysis, considering absolute and relative frequency, and inferential statistics, through the Chi-square test, with a $5 \%$ of significance for all analyses.

Results: an expressive presence of communicative deficits, in the answers presented by the therapists, was seen. In the protocol answered by the parents, it was also possible to observe the same trend, since the children failed to score in several items of Subscale I.

Conclusion: parents and therapists evidenced changes in the communicative skills of the children surveyed, and emphasized that therapists, who have technical linguistic knowledge, like parents, can also be good informants about their children's communicative development process.

Keywords: Autistic Spectrum Disorder; Language; Communication; Family; Speech, Language and Hearing Sciences 


\section{INTRODUCTION}

Autistic Spectrum Disorder (ASD) has been the subject of research and debate among scholars for decades, more precisely since its first description in the 1940 's ${ }^{1}$. Since then, scholars have mobilized around this disorder, seeking to understand and consequently explain all processes that characterize it.

In 1943, Leo Kanner published the article "Autistic Affective Contact Disorders" in the Nervous Child Journal. He described, for the first time, 11 cases of children with autism and reported the behavior and education of each child aged two to eight years. ${ }^{1}$ One year after Kanner's publication, Hans Asperger, an Austrian psychiatrist and researcher, wrote the article "Autistic psychopathy in childhood", which described children who had difficulty to socially integrate into groups $^{2}$. In 1981, Lorna Wing published an article on the syndrome described by Hans Asperger. The author described a series of cases showing similar symptoms, pointing out a notion of a spectrum of autistic disorders based on a triad of disorders ${ }^{3}$.

Autism, currently known as Autism Spectrum Disorder (ASD), is described in the newest edition of the Diagnostic and Statistical Manual of Mental Disorders, The DSM- $V^{4}$, of the American Psychiatric Association (APA). Thus, autism is part of a spectrum, that is, the disorder is a set of behaviors and must be characterized according to its severity. In this new classification, the ASD is a set of manifestations that are characterized by persistent alterations in communication and social interaction, in addition to restricted and repetitive patterns of behavior, interests, or activities ${ }^{4}$.

The impairment of reciprocal social interaction is wide and persistent. There may be a marked impairment of the use of multiple non-verbal behaviors that regulate social interaction and communication. Communication impairment is also accentuated and persistent, affecting both verbal and non-verbal skills. There may be a delay or total absence of spoken language development ${ }^{5}$.

In view of social and language changes described in children with ASD, parents can often be pointed out as informers of their children's communicative development, which may evidence the existence of delays in language acquisition and deficits in social interaction. This detection drives them at early stages to seek professional help ${ }^{6}$.

The therapist's perception of the communication skills of children with ASD may play a fundamental role in outlining the intervention process. At the same time, the parents' reports on these skills may also provide essential information for this process, but they are often unclear, due to the use of long and complex protocols. Thus, verifying the possibility of applying a simple protocol answered by parents and a more extensive protocol answered by speech therapists has clear relevance for clinical practice.

Therefore, considering the language development of children with ASD from the social context in which they live, this study aimed at describing the communication skills of children with ASD, considering the clinical and family perspective.

\section{METHODS}

This study was approved by the Ethics Committee and Research Involving Human Beings of the Health Sciences Center of the Federal University of Pernambuco, Brazil, under opinion no. 2,106,800.

This is a descriptive quantitative research. The guardians and therapists were explained the objectives of the research and asked to sign an Informed Consent (IC), which were duly signed.

Also, following the recommendations of ethics and research with human beings, the confidentiality of the identity of the participants was kept.

Data collection was performed at the Clinic School of Speech Therapy Prof. Fábio Lessa of the Federal University of Pernambuco (UFPE) during the activities of the research project entitled "Speech Therapy and Autism: Know, Intervene, and Include."

The parents and therapists of ten children with ASD of both genders, from the metropolitan region of Recife, aged between three and seven years old, participated in this research regardless of whether the impairment was mild, moderate, or severe. The four therapists had known the children for ten months. The therapists were female, three were graduating in the 8th period (4th year), the last semester of the Speech Therapy course, and only one was in the 6th period (3rd year). Ten guardians of children with ASD also participated, and the participation was effected by filling a questionnaire in the form of an interview.

Data collection was performed with the application of two protocols. The first was the Autism Treatment Evaluation Checklist (ATEC) ${ }^{7}$ (Annex 1), which was applied to the children's parents. This checklist is designed to assess the effectiveness of treatments and monitor how an individual progresses over time. The ATEC is used by parents, researchers, and schools, medical clinics, and a variety of health professionals. The purpose of the ATEC is to measure changes in 
an individual due to multiple interventions, that is, the difference between the initial (baseline) ATEC scores and the later ATEC scores. The scale, however, has normative data that allow the comparison of an individual with others. The ATEC assesses 77 items, such as whether the child knows its name, makes eye contact with others, or has symptoms such as enuresis, diarrhea, constipation, and so on. They are divided into four sub-groups that measure the child in terms of Speech/Language/Communication (14 items), Sociability (20 items), Sensory/cognitive perception (18 items), and Health/Physics/Behavior (25 items). ${ }^{7}$ For this study, the first sub-group, consisting of 14 items that are specific about speech, language, and communication, will be analyzed.

The second is the Protocol for Assessment of Pragmatic Skills of Children with Autism Spectrum Disorders (PP) ${ }^{8}$, which was answered by the therapists. This protocol is composed of 29 questions plus three further questions that were considered relevant for this study, totaling 32 questions. The protocol covers aspects of verbal and non-verbal communication skills and considers social understanding and the communicative context.

The interviews with parents were carried out individually in an attendance room at the Clínica Escola de Fonoaudiologia of the institution of origin during the speech therapy sessions of children without a pre-scheduled time. The interviews lasted an average of 30 minutes.
The therapists were given the questionnaires referring to each patient they were responsible for, and they answered the questionnaires individually.

Data collection was carried out between July and November 2018. Data were collected with parents and therapists of each child at the same time, thus avoiding divergences of answers related to time spans, since the protocols should be answered considering the communicative situation presented by the children at the time of collection.

Data were entered into a Microsoft Excel digital spreadsheet. Descriptive statistical analysis was performed analyzing absolute and relative frequency and inferential statistics using the Chi-square Association test in the software SPSS, version 21, with a $5 \%$ significance for all analyses. After statistical treatment, the data were organized into tables.

\section{RESULTS}

The survey participants were between three and seven years old, $90 \%$ male and $10 \%$ female, that is, only one girl.

Table 1 shows the results of the parents' responses to each statement of Subscale I (Speech, Language and Communication) of the ATEC scale. ${ }^{7}$ The mean percentage of the 14 items of the ATEC scale that deal with Speech, Language and Communication was calculated from the answers "Not True" (NT), when the child did not present communicative behavior; "More or less True" (ML), when it sometimes occurred; and "True" when it was already consolidated by the child. 
Table 1. Answers obtained from the application of the questionnaire Autism Treatment Evaluation Checklist to those responsible for children with Autism Spectrum Disorder

\begin{tabular}{lcccccc}
\hline \multirow{2}{*}{ Variable } & \multicolumn{2}{c}{ Not true (NT) } & \multicolumn{2}{c}{$\begin{array}{c}\text { More or less true } \\
\text { (ML) }\end{array}$} & \multicolumn{2}{c}{ True (T) } \\
\cline { 2 - 7 } & $\mathbf{N}$ & $\%$ & $\mathbf{N}$ & $\%$ & N & $\%$ \\
\hline 1. Know their own name & 5 & 50.0 & 1 & 10.0 & 4 & 40.0 \\
2. Respond to "no" or "stop" & 1 & 10.0 & 4 & 40.0 & 5 & 50.0 \\
3. Can obey certain orders & 0 & 0.0 & 7 & 70.0 & 3 & 30.0 \\
4. Can use one word at a time. e.g.: no, eat, water & 3 & 30.0 & 0 & 0.0 & 7 & 70.0 \\
5. Can use two words together. e.g.: I don't want to go. & 5 & 50.0 & 2 & 20.0 & 3 & 30.0 \\
6. Can use three words together. e.g.: I don't want milk. & 8 & 80.0 & 0 & 0.0 & 2 & 20.0 \\
7. Know ten or more words & 4 & 40.0 & 0 & 0.0 & 6 & 60.0 \\
8. Can use sentences with four or more words & 8 & 80.0 & 1 & 10.0 & 1 & 10.0 \\
9. Explain what the child wants & 3 & 30.0 & 5 & 50.0 & 2 & 20.0 \\
10. Ask questions with sense & 7 & 70.0 & 1 & 10.0 & 2 & 20.0 \\
11. Child's language is often relevant/meaningful & 7 & 70.0 & 2 & 20.0 & 1 & 10.0 \\
12. Often use several successive sentences & 7 & 70.0 & 1 & 10.0 & 2 & 20.0 \\
13. Maintain a reasonably good conversation & 8 & 80.0 & 2 & 20.0 & 0 & 0.0 \\
14. Have normal communication skills for the age & 8 & 80.0 & 1 & 10.0 & 1 & 10.0 \\
\hline
\end{tabular}

The 14 questions referring to the aspects of Speech, Language and Communication reveal that a large part of the parents marked the item "Not true" (NT) in the following situations: knowing their own name (50\%); able to use two words together (50\%); able to use three words together $(80 \%)$; able to use sentences with four or more words (80\%); ask meaningful questions $(70 \%)$; use relevant/meaningful language (70\%); frequently use several successive sentences (70\%); maintain a reasonably good conversation (80\%); and have a normal communication ability for the child's age (80\%).

The answers "More or Less True" (ML) were largely marked by parents in the following situations: obeying certain orders $(70 \%)$ and explaining what the child wants (50\%).

The veracity $(\mathrm{V})$ of questions was present in most answers with the following statements: answering to "no" or "stop" (50\%), able to use one word at a time $(70 \%)$ and knowing ten or more words (60\%).

Table 2 shows information regarding the Protocol for Assessment of Pragmatic Skills of Children with Autism Spectrum Disorder (PP) ${ }^{8}$ obtained through the responses of the children's therapists. The therapists answered the questions based on the following options: always, frequently, sometimes, rarely, or never. 
Table 2. Answers obtained from the application of the Protocol for the Assessment of Pragmatic Skills of Children with Autism Spectrum Disorders to the therapists of children with Autism Spectrum Disorder

\begin{tabular}{|c|c|c|c|c|c|c|c|c|c|c|}
\hline \multirow{2}{*}{ VARIABLE } & \multicolumn{2}{|c|}{ Always } & \multicolumn{2}{|c|}{ Frequently } & \multicolumn{2}{|c|}{ Sometimes } & \multicolumn{2}{|c|}{ Rarely } & \multicolumn{2}{|c|}{ Never } \\
\hline & $\mathbf{N}$ & $\%$ & $\mathbf{N}$ & $\%$ & $\mathbf{N}$ & $\%$ & $\mathbf{N}$ & $\%$ & $\mathbf{N}$ & $\%$ \\
\hline 1- Looks at the adult & 0 & 0.0 & 3 & 30.0 & 5 & 50.0 & 2 & 20.0 & 0 & 0.0 \\
\hline 2- Interacts with the adult & 3 & 30.0 & 2 & 20.0 & 3 & 30.0 & 2 & 20.0 & 0 & 0.0 \\
\hline 3- Mainly uses speech to communicate & 1 & 10.0 & 2 & 20.0 & 2 & 20.0 & 1 & 10.0 & 4 & 40.0 \\
\hline 4- Uses mainly non-verbal sounds to communicate & 1 & 10.0 & 2 & 20.0 & 3 & 30.0 & 3 & 30.0 & 1 & 10.0 \\
\hline 5- Mainly uses gestures to communicate & 2 & 20.0 & 3 & 30.0 & 3 & 30.0 & 2 & 20.0 & 0 & 0.0 \\
\hline 6- Makes itself easily understood & 2 & 20.0 & 2 & 20.0 & 4 & 40.0 & 2 & 20.0 & 0 & 0.0 \\
\hline $\begin{array}{l}\text { 7- Answers (understands) simple questions (where the car } \\
\text { is, what do you want...) }\end{array}$ & 1 & 10.0 & 4 & 40.0 & 1 & 10.0 & 2 & 20.0 & 2 & 20.0 \\
\hline $\begin{array}{l}\text { 8- Answers complex questions (why did he do it? what did } \\
\text { you do at school?) }\end{array}$ & 0 & 0.0 & 1 & 10.0 & 2 & 20.0 & 1 & 10.0 & 6 & 60.0 \\
\hline 9- Answers with single words or two-word phrases & 0 & 0.0 & 5 & 50.0 & 1 & 10.0 & 0 & 0.0 & 4 & 40.0 \\
\hline $\begin{array}{l}\text { 10- Answers with complete sentences with complex } \\
\text { structures }\end{array}$ & 0 & 0.0 & 0 & 0.0 & 2 & 20.0 & 1 & 10.0 & 7 & 70.0 \\
\hline icts to request actions or objects & 2 & 20.0 & 2 & 20.0 & 4 & 40.0 & 2 & 20.0 & 0 & 0.0 \\
\hline & 0 & 0.0 & 2 & 20.0 & 1 & 10.0 & 1 & 10.0 & 6 & 60.0 \\
\hline 13- Makes appropriate comments & 0 & 0.0 & 2 & 20.0 & 3 & 30.0 & 0 & 0.0 & 5 & 50.0 \\
\hline $\begin{array}{l}\text { 14- Uses single words and two-word phrases to } \\
\text { communicate }\end{array}$ & 1 & 10.0 & 2 & 20.0 & 3 & 30.0 & 0 & 0.0 & 4 & 40.0 \\
\hline $\begin{array}{l}\text { 15- Uses complete sentences and complex structures to } \\
\text { communicate }\end{array}$ & 0 & 0.0 & 0 & 0.0 & 2 & 20.0 & 1 & 10.0 & 7 & 70.0 \\
\hline 16- Gives orders & 0 & 0.0 & 2 & 20.0 & 2 & 20.0 & 2 & 20.0 & 4 & 40.0 \\
\hline leasure, fear, or discontent clearly & 2 & 20.0 & 5 & 50.0 & 1 & 10.0 & 2 & 20.0 & 0 & 0.0 \\
\hline $\begin{array}{l}\text { 18- Changes communicative turns properly (hold a } \\
\text { conversation) }\end{array}$ & 1 & 10.0 & 2 & 20.0 & 3 & 30.0 & 1 & 10.0 & 3 & 30.0 \\
\hline 19- Plays make-believe & 2 & 20.0 & 0 & 0.0 & 2 & 20.0 & 3 & 30.0 & 3 & 30.0 \\
\hline $\begin{array}{l}\text { 20- Makes it clear when it does not want to do something } \\
\text { properly }\end{array}$ & 2 & 20.0 & 2 & 20.0 & 5 & 50.0 & 1 & 10.0 & 0 & 0.0 \\
\hline $\begin{array}{l}\text { 21- Uses crying, tantrums or aggression when frustrated or } \\
\text { to interrupt some activity }\end{array}$ & 5 & 50.0 & 3 & 30.0 & 2 & 20.0 & 0 & 0.0 & 0 & 0.0 \\
\hline $\begin{array}{l}\text { 22- Produces decontextualized or non-functional speech, } \\
\text { sounds, or gestures (stereotypy) }\end{array}$ & 2 & 20.0 & 3 & 30.0 & 3 & 30.0 & 2 & 20.0 & 0 & 0.0 \\
\hline 23- Start & & 10.0 & 2 & 20.0 & 2 & 20.0 & 1 & 10.0 & 4 & 40.0 \\
\hline 24- Tells stories 0 & 0 & 0.0 & 1 & 10.0 & 1 & 10.0 & 1 & 10.0 & 7 & 70.0 \\
\hline $\begin{array}{l}\text { 25- Comments on what is happening or could happen (it will } \\
\text { fall..., one, two, one more...) }\end{array}$ & 1 & 10.0 & 3 & 30.0 & 0 & 0.0 & 1 & 10.0 & 5 & 50.0 \\
\hline 26- Includes the adult in the game & 1 & 10.0 & 3 & 30.0 & 2 & 20.0 & 4 & 40.0 & 0 & 0.0 \\
\hline 27- Isolated plays in repetitive activities & 2 & 20.0 & 1 & 10.0 & 6 & 60.0 & 0 & 0.0 & 1 & 10.0 \\
\hline $\begin{array}{l}\text { 28- Is attentive and understands facial expressions and } \\
\text { prosody }\end{array}$ & 2 & 20.0 & 1 & 10.0 & 4 & 40.0 & 1 & 10.0 & 2 & 20.0 \\
\hline $\begin{array}{l}\text { 29- Uses facial expressions and prosodic variations to } \\
\text { express itself }\end{array}$ & 1 & 10.0 & 1 & 10.0 & 3 & 30.0 & 2 & 20.0 & 3 & 30.0 \\
\hline *30- Answers to his/her own name & 2 & 20.0 & 3 & 30.0 & 2 & 20.0 & 2 & 20.0 & 1 & 10.0 \\
\hline *31- Uses the toy in a functional way & 3 & 30.0 & 3 & 30.0 & 4 & 40.0 & 0 & 0.0 & 0 & 0.0 \\
\hline *32- Performs imitation & 2 & 20.0 & 5 & 50.0 & 2 & 20.0 & 1 & 10.0 & 0 & 0.0 \\
\hline
\end{tabular}


The PP showed quantitative data on children's development and communication based on a mean percentage of the 32 items of the questionnaire.

The items that had the answer "never" marked by most therapists were use of speech mainly to communicate (40\%); answering complex questions (60\%); answer with complete sentences and complex structures (70\%); ask for information (ask questions) (60\%); make appropriate comments (50\%); use single words and two-word sentences to communicate (40\%); use complete sentences and complex structures to communicate $(70 \%)$; giving orders (40\%); start communication (40\%); telling stories or reporting facts $(70 \%)$; and commenting on what is happening or might happen (50\%).

Most therapists marked the answer "sometimes" in seven items: look at the adult (50\%); make itself understood easily (40\%); interact to ask for actions or objects (40\%); make it clear when the child do not want to do something properly (50\%); playing isolated in repetitive activities (60\%); attentive and understand facial expressions and prosody (40\%); and use the toy in a functional way (40\%).
The answer "often" was marked by most therapists in the following items: answer (understand) simple questions (40\%); answer with single words or two-word sentences (50\%); expressing pleasure, fear, or discontent clearly; and answer to one's own name $(30 \%)$ and imitate (50\%).

The answer "always" was mostly marked in only one questioned item which referred to using crying, tantrums, or aggression when frustrated or interrupting some activity. The answer appeared in $50 \%$ of the sample. Likewise, the answer "rarely" occurred only in the item including the adult in the game, being marked by $40 \%$ of therapists.

The application of PP showed a great variability in the means found in the population of this study based on the answers obtained by therapists.

Table 3 shows a correlation performed between the answers obtained by the two protocols used in the research based on their inferential correlation between variables using the Chi-square test. Thus, the results that were shown to be statistically significant when crossing the ATEC and PP variables were analyzed, that is, an analysis was performed based on the confrontation of responses between parents and therapists.

Table 3. Correlation of the variables question 4 of Autism Treatment Evaluation Checklist and question 5 of the Protocol for the Assessment of Pragmatic Skills of Children with Autism Spectrum Disorders

\begin{tabular}{|c|c|c|c|c|c|c|c|}
\hline \multirow{3}{*}{ VARIABLE } & \multicolumn{6}{|c|}{ ATEC- Question 4. Can use one word at a time } & \multirow{3}{*}{ p-value } \\
\hline & \multicolumn{2}{|c|}{ Not true } & \multicolumn{2}{|c|}{ More or less True } & \multicolumn{2}{|c|}{ True } & \\
\hline & N & $\%$ & $\mathbf{N}$ & $\%$ & $\mathbf{N}$ & $\%$ & \\
\hline \multicolumn{8}{|c|}{$\begin{array}{l}\text { PP - Question } 5 \text {. Mainly uses gestures to } \\
\text { communicate }\end{array}$} \\
\hline Always & 2 & 66.7 & 0 & 0.0 & 0 & 0.0 & \\
\hline Frequently & 1 & 33.3 & 0 & 0.0 & 2 & 28.6 & $0.048^{*}$ \\
\hline Sometimes & 0 & 0.0 & 0 & 0.0 & 3 & 42.9 & \\
\hline Rarely & 0 & 0.0 & 0 & 0.0 & 2 & 28.6 & \\
\hline Never & 0 & 0.0 & 0 & 0.0 & 0 & 0.0 & \\
\hline
\end{tabular}

Test: Chi-square; significance $p<0.05$

Although Table 3 shows a correlation between Question 4-ATEC and Question 5-PP, there was a great variability of answers in the questions. It was possible to observe that three parents reported that it was "not true" that the children were able to use a word at a time; of these, two therapists pointed out that the children "always" used gestures to communicate and one therapist pointed out that the child used gestures "frequently." Furthermore, according to the parents' responses, it is "true" that seven children can use one word at a time; of these two use gestures frequently, three sometimes, and two rarely. 


\section{DISCUSSION}

The ATEC used for analysis of communicative skills of children with ASD, as described in Table 1, based on the parents' responses was used in a study ${ }^{9}$ which, through a longitudinal study, analyzed ATEC scores in subgroups with ASD and obtained sensitive results in mean scores over time. Other researchers ${ }^{10}$ monitored the evolution over time of 22 school-age children with ASD using the ATEC; parents were responsible for completing the protocol. The initial total ATEC scores predicted $64 \%$ of variation in scores in the subsequent follow-up. However, there was also a considerable variation in individual children's scoring patterns over time, providing evidence of the effectiveness of ATEC with significant correlations in monitoring the evolutionary process of children with ASD over time or in response to intervention processes. The ATEC was also ${ }^{11}$ a safe and valid tool to assess treatments and the progress of individuals with ASD, even compared to other more scientifically widespread protocols, such as the Child Autism Rating Scale (CARS).

From the analysis of ATEC values, children failed to score in several items of Subscale I, such as knowing their own name; use one word at a time; use two words together; use three words together; use sentences with four or more words; explain what the child wants; ask meaningful questions; present relevant language with meaning; use several successive sentences; have a reasonably good conversation; and have normal communication skills for the child's age.

The results found, which show the expressive language of children with ASD, converge with data presented in a study by Kanner ${ }^{1}$ with 11 children, in which eight had acquired language, although often with delay, and three persevered with complete mutism. In the present study, most parents indicated that their children were verbal, as they could use one word at a time to communicate. Some parents reported that their children also produced sentences, but $30 \%$ of the surveyed sample presented themselves as non-verbal, as they were not able to express themselves through words. Such findings are similar as results of other studies $^{12}$ that describe a significant delay or a total absence of spoken language in a relevant proportion of children with ASD, which may extend into adulthood ${ }^{6,12,13}$.

Deficits in spoken language understanding are pointed out as a characteristic of children with ASD $^{12,14}$. In this study, based on the parents' answers regarding understanding language, most children are able to understand ten or more words.

Considering the age of the children in this research, only $20 \%$ of them can use sentences with three words. When this number rises to the use of four or more words, the percentage drops to $10 \%$, showing a low communicative performance regarding the use of sentences.

The greatest communicative deficits of children with ASD are in the pragmatic aspects and in the structuring of narratives. Such limitations prevent these individuals from understanding, initiating, and maintaining a conversation ${ }^{15,16}$.

In view of the changes in communication described by parents, most (80\%) showed that the children had an altered communication compared to children in the same age group. This finding shows the awareness of parents of the alterations in the language development of children with ASD. Language deficits, widely described in the literature, are considered the central issue of this disorder ${ }^{12,16}$.

The results in Table 2 address the communicative abilities of children with ASD based on the therapists' answers. There was a great variability in the answers of therapists in all questions asked, but with an expressive presence of communicative deficits.

There was a great variability in the therapists' responses to the following questions: interacts with the adult; uses mostly non-verbal sounds to communicate; mainly uses gestures to communicate; change communicative turns in an appropriate way; play makebelieve; produces speech, sounds or gestures out of context; uses facial expressions and prosodic variations to communicate; and responds to the own name.

The studied sample describes the behavior of the eye contact ability. Gazing is one of the fundamental non-verbal indicators to elaborate correct interpretations of an utterance. Several experiments show that children with ASD do not pay attention to the interlocutor's gaze and therefore have difficulties in formulating interpretations, since typical two-year-old children seek the mother's gaze to understand to which object in the context their words refer $^{16}$. This finding may influence the communicative deficits found in the studied sample.

Regarding speech, most therapists reported that children never used it as the main form of communication. Non-verbal sounds appeared as the second most used form of communication and there was a greater tendency to use gestures. A previous study ${ }^{17}$ also pointed out this evidence. The authors analyzed 
the verbal and non-verbal communication skills of six children diagnosed with language delay secondary to ASD. The gestural communicative medium appeared more frequently, expressing a wide variety of communicative functions.

Receptive language was pointed out by therapists with little commitment. Authors ${ }^{18}$ in a clinical study of children with ASD indicated deficits in both expressive and receptive communicative means.

The skills that involve the social use of pragmatic language represented a quantitative deficit in the studied group based on the therapists' responses.

There is a list of inappropriate pragmatic behaviors present in the repertoire of individuals with ASD: inappropriate use of eye contact; difficulty reading emotions in facial expressions; difficulties expressing emotions in facial expressions; difficulty in understanding communicative and non-verbal gestures; lack of use of communicative and non-verbal gestures; difficulties with conversational repair; absence of prosody (i.e., voice melody); difficulties with maintaining the topic; talks in exaggeratedly; lack of social initiations with others; difficulties with conversational reciprocity; perseverance in language; difficulties with topic coherence; use of tangential language; difficulties in interpreting abstract language; difficulties showing interest in others; difficulties with friendships; and restricted and repetitive interests ${ }^{19}$.

It is important to highlight that the commitment in the general functioning of the pragmatic language of individuals with ASD is significant ${ }^{19}$ and is present in the questionnaire ${ }^{8}$ that was the object of analysis of this study and, based on the responses of therapists, they were also significant deficits in the pragmatic language of the children.

Impaired pragmatic language (i.e., the use of language for social interaction) is a hallmark of ASD. Authors carried out a study with 29 school-age boys diagnosed with ASD who had pragmatic language deficits using semi-naturalistic and standardized assessment methods ${ }^{20}$.

Still with regard to pragmatic aspects, a survey ${ }^{21}$ investigated the communication of 50 children diagnosed with ASD following the parameters of the pragmatic theory. The children were submitted to a game situation with a speech therapist and an adult. The results indicated that the communication of adults was essentially verbal, while that of children was fundamentally gestural; in addition, communication initiatives were similar between adults and children. In this research, therapists emphasized that $40 \%$ of children never initiated communication.

Several authors have described this communicative inability in children with ASD, and a relevant fact to be highlighted in this study is that most therapists pointed out that children never tell stories or report facts. Communicative exchanges are extremely important to establish a union between an individual and another, evidencing the importance of initiating communicative exchanges, especially in individuals with ASD $^{22}$.

The findings of the present study corroborate several authors who have pointed out to pragmatic ability as one of the most affected in children with ASD ${ }^{14,15,19-22}$.

The social use of language is pointed out as highly affected by most authors who carry out studies on the communicative skills of children with ASD. This may be related to the analysis of some assumptions ${ }^{23}$ that point to the fact that, regardless of whether individuals with ASD have some linguistic competence or not, they may not communicate with others. Therefore, for the author, the way to assess areas of language has been a center of concern for some researchers.

Thus, there is a need to assess all communicative skills and observe how they relate to each other, since it is not clear how these skills relate and influence each other, thus requiring further studies to assess these relationships.

As seen, children with ASD showed changes in communication based on the responses of parents and their therapists. Next, the correlations between the responses obtained by these two groups will be discussed because both groups are present in the communicative daily life of these children.

An important finding in this research is the correlation between questions 4-ATEC and question 5-PP. Table 03 shows that three children could not use one word at a time; of these, three therapists showed that they used gestures to communicate, demonstrating that non-verbal children have a greater tendency to communicate through gestures. Such data do not corroborate the studies of other authors ${ }^{16,24}$ who pointed out that children with ASD do not use gestures as an attempt to replace the linguistic code, unlike what occurs in individuals with hearing loss who, because they have a good interaction, make use of gestures as a form of communication.

Analyzing the responses of the two protocols used allows perceiving both the views of parents of children with ASD and their therapists. The results of a recent survey revealed the importance of communication 
guidelines for parents and caregivers of children with ASD, since, after guidance sessions, there was a change in the view of parents towards the communication process of their children in different situations ${ }^{25}$. Another study evaluated the functional profile of communication and social relationship data of children with ASD and children with typical development (TD) based on information provided by parents and teachers. The results revealed that the answers of both groups were adequate in identifying specific characteristics of children with ASD and TD ${ }^{26}$.

Authors ${ }^{27}$ point to the fact that parents provide such information without the influence of professional demands regarding the need for good results.

In general terms, it is evident by this research that parents and therapists had the same understanding regarding the performance of difficulties and skills in communication of children. The convergence of data found for the communicative alterations of children with ASD allows concluding that parents can be good informants of their children's communicative process, thus emphasizing the importance of the insertion of the family during the therapeutic process, making them more present and participatory in their children's communicative development process.

\section{CONCLUSION}

This research concludes that both parents and therapists reported deficits in both verbal and non-verbal communication skills of children with ASD. However, it is necessary to draw attention to the sample size, which does not allow making generalizations, thus, requiring further studies to confirm the results.

\section{ACKNOWLEDGEMENTS}

To all involved participants, the Clínica Escola de Fonoaudiologia Prof. Fábio Lessa of the Federal University of Pernambuco-UFPE for granting the space for the research; to the subjects with Autism Spectrum Disorder, their parents, and therapists participating in the project, who made this study possible.

\section{REFERENCES}

1. Kanner L. Autistic disturbances of affective contact. Nerv Child. [jornal on the internet] 1943 [accessed on 2018 apr 09]; (2):217-50. Available at: http:// www.neurodiversity. com/library_kanner 1943.pdf
2. Asperger H. 'Autistic psychopathy' in childhood. In: Frith U. Autism and Asperger syndrome, editor. Cambridge: Cambridge University Press; 1944/1992. p. 37-62.

3. Wing L. Asperger's syndrome: a clinical account. Psychol Med. 1981;11(1):115-29.

4. Associação Americana de Psiquiatria, APA. DSM V - Manual diagnóstico e estatístico de transtornos mentais. 5a. Ed. Porto Alegre: Artmed; 2014.

5. Dornelles C. Manual diagnóstico e estatístico de transtornos mentais 4 a. Ed. rev. (DSM-IV-TR). São Paulo: Artes Médicas, 2002.

6. Backes B, Zanon R, Bosa C. Identificação dos primeiros sintomas do autismo pelos pais. Psic.: Teor. e Pesq. 2014;30(1):25-33.

7. Rimland B, Edelson M. Autism treatment evaluation checklist. Autism Research Institute [database on the internet]; San Diego, CA. 1999. [accessed on 2018 jun 12]; Available at: https://www.autismeval. com/ari-atec/report1.html

8. Fernandes F. Assessment of pragmatic abilities of children with Autism Spectrum Disorders. ACR. 2021. No prelo.

9. Mahapatra S, Khokhlovich E, Martinez S, Kannel B, Edelson S, Vyshedskiy A. Longitudinal epidemiological study of autism subgroups using Autism Treatment Evaluation Checklist (ATEC) score. J Autism Dev Disord. 2018;50(5):1497-508.

10. Magiati I, Moss J, Yates R, Charman T, Howlin P. Is the Autism Treatment Evaluation Checklist a useful tool for monitoring progress in children with autismo spectrum disorders? J Intellect Disabil Res. 2011;55(3):302-12

11. Freire $M$, André A, Kummer A. Confiabilidade teste-reteste e validade concorrente da Lista de Verificação de Avaliação do Tratamento do Autismo (ATEC). J.bras. psiquiatr. 2018;67(1):63-4.

12. Klin A. Autismo e síndrome de Asperger: uma visão geral. Rev. Bras. Psiquiatr. 2006;28(1):3-11.

13. Gadia C, Tuchman R, Rotta N. Autismo e doenças invasivas do desenvolvimento. J. Pediatria. 2004;80(2):83-94.

14. Flippin M, Reszka S, Watson L. Effectiveness of the Picture Exchange Communication System (PECS) on communication and speech for children with autism spectrum disorders: a meta-analysis. Am J Speech Lang Pathol. 2010;19(2):178-95. 
15. Perissonoto J. Linguagem da criança com Autismo. In: Perissonoto J, editor. Conhecimentos essenciais para atender a criança com autismo. São José dos Campos: Pulso; 2003. p.39-44.

16. Surian L. Autismo: informações essenciais para familiares, educadores e profissionais de saúde. São Paulo: Paulinas; 2010.

17. Campelo L, Lucena J, Lima C, Araújo H, Viana $\mathrm{L}$, Veloso $\mathrm{M}$ et al. Autismo: um estudo sobre habilidades comunicativas em crianças. Rev. CEFAC. 2009;11(4):598-606.

18. Rapin I, Dunn M. Update on the language disorders of individuals on the autistic spectrum. Brain and Development. 2003;25(3):166-72.

19. Philofsky A, Fidler D, Hepburn S. Pragmatic language profiles of school-age children with autism spectrum disorders and Williams syndrome. Am J Speech Lang Pathol. 2007;16(4):368-80.

20. Klusek J, Martin G, Losh M. A Comparison of pragmatic language in boys with autism and fragile X syndrome. J Speech Lang Ouvir Res. 2014;57(5):1692-707.

21. Fernandes F. Aspectos funcionais da comunicação de crianças autistas. Temas em desenvolvimento. 2000;9(51):25-35.

22. Miilher I, Fernandes F. Considering responsivity: a proposal for pragmatic analysis in autism spectrum. CoDAS. 2013;25(1):70-5.

23. Tager-Flusberg $\mathrm{H}$. The challenge of studying language development in children with autism. In: Menn L, Ratner N, editors. Methods for studying language production. New Jersey: Lawrence Erlbaum, 2000. p. 313-32.

24. Perissonoto J. Processo de evolução da criança com autismo. In: Perissonoto J, editor. Conhecimentos essenciais para atender a criança com autismo. São José dos Campos: Pulso; 2003. p.23-7.

25. Balestro J, Fernandes F. Caregivers' perception of children with Autism Spectrum Disorder regarding to the communicative profile of their children after a communicative orientation program. CoDAS. 2019;31(1):1-9.

26. Hyter Y, Vogindroukas I, Chelas E-N, Paparizos K, Kivrakiou E, Kaloudi V. Differentiating autismo from typical development: preliminar findings of greek versions of a pragmatic language and social communication questionnaire. Folia Phoniatr Logop. 2017;69(1-2):20-6.
27. Campos L, Fernandes F. School profile and language and cognitive abilities of children and adolescents with autism spectrum disorders. CoDAS. 2016;28(3):234-43. 


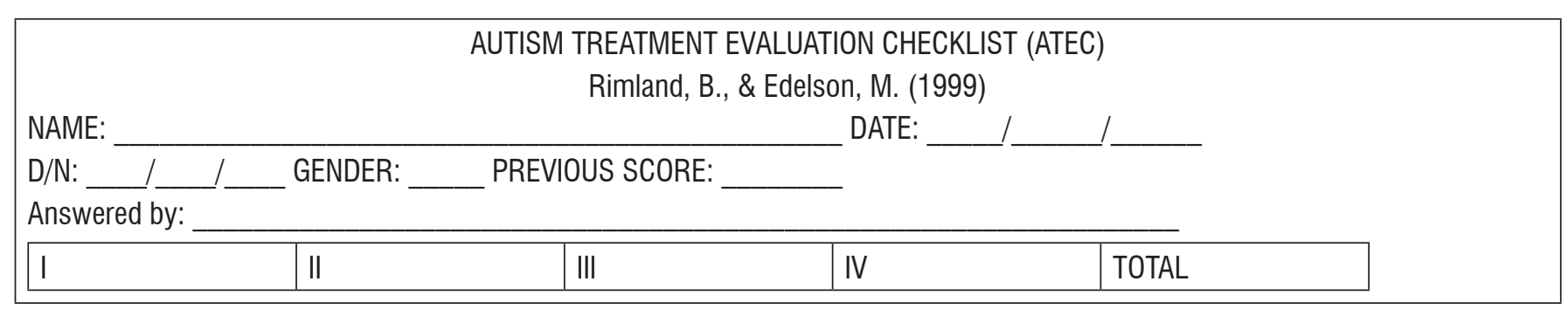

Please mark with an " $X$ " the option that is most suitable:

\section{Speech/Language/Communication Not true (nt)/ more or less (ml)/ true (t)}

1. Knows his/her own name

2. Responds to "no" or "stop"

3. Can obey certain orders

4. Can use one word at a time. e.g.: no, eat, water

5. Can use two words togethere.g.: I don't want to go.

6. Can use three words togethere.g.: I don't want milk.

7. Knows ten or more words

8. Can use sentences with four or more words

9. Explains what the child wants

10. Asks questions with sense

11. Child's language is often relevant/meaningful

12. Often uses several successive sentences

13. Maintains a reasonably good conversation

14. Has normal communication skills for the age

\begin{tabular}{|l|l|l|l|}
\hline$(\mathrm{nt})$ & $(\mathrm{ml})$ & $(\mathrm{t})$ \\
\hline & & & \\
\hline & & \\
\hline & & \\
\hline & & \\
\hline & & \\
\hline & & & \\
\hline & & \\
\hline & & \\
\hline & & \\
\hline & & & \\
\hline
\end{tabular}

\section{Sociability: non-descriptive (nd) / more or less (ml) / describes my child (d)}

1. Seems to be closed in on him/herself - it is not possible to interact with him/her

2. Does not pay attention to people

3. Shows little or no attention when we talk to the child

4. Not cooperative and tough.

5. No eye contact

6. Prefers to be left alone

7. Does not show affection

8. Does not greet the parents

9. Avoids contact with other people

10. Does not imitate

11. Does not like to be hugged or caressed

12. Does not share/shows things to others

13. Does not say goodbye by waving

14. He/she is nasty / disobedient

15. Throws tantrums

16. No friends/partners

17. Smiles very little

18. Insensitive to the feelings of others

19. Not interested in pleasing others

20. Is indifferent when parents leave 
III. Sensory/Cognitive Capacity: not descriptive (nd) / little descriptive (Id) / very descriptive (vd)

\begin{tabular}{|c|c|c|c|}
\hline \multirow{2}{*}{\multicolumn{4}{|c|}{ 1. Answers to his/her own name }} \\
\hline & & & \\
\hline \multicolumn{4}{|l|}{ 2. Recognizes when praised } \\
\hline \multicolumn{4}{|l|}{ 3. Looks at people and animals } \\
\hline \multicolumn{4}{|l|}{ 4. Watches cartoons on TV } \\
\hline \multicolumn{4}{|l|}{ 5. Draws, colors, makes art objects } \\
\hline \multicolumn{4}{|l|}{ 6. Plays with toys correctly } \\
\hline \multicolumn{4}{|l|}{ 7. Has an appropriate facial expression } \\
\hline \multicolumn{4}{|l|}{ 8. Understands TV Stories } \\
\hline \multicolumn{4}{|l|}{ 9. Understands explanations } \\
\hline \multicolumn{4}{|l|}{ 10. Is aware of the environment around him/her } \\
\hline \multicolumn{4}{|l|}{ 11. Is aware of the danger } \\
\hline \multicolumn{4}{|l|}{ 12. Demonstrates imagination } \\
\hline \multicolumn{4}{|l|}{ 13. Starts activities } \\
\hline \multicolumn{4}{|l|}{ 14. Dresses alone } \\
\hline \multicolumn{4}{|l|}{ 15. Is curious, interested } \\
\hline \multicolumn{4}{|l|}{ 16. Dares, explores } \\
\hline \multicolumn{4}{|l|}{ 17. Tuned in, does not seem to be in the clouds } \\
\hline 18. Looks where others look & & & \\
\hline
\end{tabular}

IV. Health/Physical Aspects/Behavior: Not a problem (np) / Small problem (sp) / Moderate problem (md) / Serious problem (sq)

1. Has nocturnal enuresis (wetting the bed)

2. Urinates in pants/diaper

3. Defecates in pants or diaper

4. Has diarrhea

5. Has constipation

6. Has problem sleeping

7. Eats a lot / eats very little

8. Limited diet, does not accept any type of food

9. Is hyperactive

10. Is lethargic

11. Hurts itself

12. Hurts others

13. Is destructive

14. Is sensitive to noise

15. Is anxious/in fear

16. Is sad/cries

17. Has convulsions

18. Has obsessive speech/language

19. Has rigid Routines

20. Screams/Speaks aloud

21. Requires that things always be done the same way

22. Often gets agitated

23. Is insensitive to pain

24. Has fixation for certain objects/themes

25. Makes repetitive gestures/movements

\begin{tabular}{|l|l|l|l|}
\hline (np) & $(\mathrm{sp})$ & $(\mathrm{md})$ & $(\mathrm{sg})$ \\
\hline & & & \\
\hline & & & \\
\hline & & & \\
\hline & & & \\
\hline & & & \\
\hline & & & \\
\hline & & & \\
\hline & & & \\
\hline & & & \\
\hline & & & \\
\hline & & & \\
\hline & & & \\
\hline & & & \\
\hline & & & \\
\hline & & & \\
\hline & & & \\
\hline & & & \\
\hline
\end{tabular}

